\title{
Spectral Enhancement of Imagery for Small Inland Water Bodies Monitoring: Utilization of UAV-Based Data
}

\author{
Jitka Komarkova ${ }^{1 *}$, Ivana Cermakova ${ }^{1}$, Pavel Sedlak ${ }^{1}$, Jakub Jech ${ }^{1}$ \\ ${ }^{1}$ Faculty of Economics and Administration, University of Pardubice, CZECH REPUBLIC
}

*Corresponding Author: jitka.komarkova@upce.cz

Citation: Komarkova, J., Cermakova, I., Sedlak, P. and Jech, J. (2019). Spectral Enhancement of Imagery for Small Inland Water Bodies Monitoring: Utilization of UAV-Based Data. Journal of Information Systems Engineering \& Management, 4(4), em0102. https:// doi.org/10.29333/jisem/ 6346

Published: December 7, 2019

\begin{abstract}
The article describes a way for identification of land cover types and consequently land cover changes around a small water body, which is based on spectral enhancement of RGB UAV-based data. A middleclass unmanned aerial vehicle (UAV) - DJI Phantom 3 Pro, was used for data collection. UAV represents a cheap and on-demand available solution for remote data sensing. Its utilization is limited by weather conditions and particular legal regulations must be followed. The article is focused on a monitoring of a small water body and its surrounding by spectral enhancement. Spectral indices, which are calculated only from the visible bands, are used to identify particular land cover types: Color Index of Vegetation Extraction (CIVE), Excess Green (ExG), Excess Red (ExR), Green Leaf Index (GLI), Normalized Green-Red Difference Index (NGRDI), Red-Green-Blue Vegetation Index (RGBVI), Visible Atmospherically Resistant Index (VARI), and ExG - ExR difference. Low pass filtering was used for post-processing and results were simply visualised in a form of classified raster (by natural breaks - Jenks). Even this simple spectral enhancement of imagery supports its visual interpretation. Visible spectral indices highlight particular land cover types, namely green vegetation and water surface but other types of land cover can be distinguished as well.
\end{abstract}

Keywords: small water bodies, UAV, spectral enhancement, visible indices, spectral indices

\section{INTRODUCTION}

Monitoring land cover changes and particularly water bodies represents an important contemporary issue of our society. It means that society is interested in new findings, which can help to understand how the Earth and its components (biophysical spheres, e.g. hydrosphere and biosphere) behave. Understanding functions, relationships, and rules can, beside others, support landscape management and further sustainable development. Studies focusing on land cover/land use change are often realized at national or international level. The local level of the monitoring of land cover/land use change and water bodies is important too but it is not so frequently covered by the studies because it may require a higher spatial resolution that satellite imagery provides.

Remotely sensed images are very often used for observation and monitoring changes of landscape and terrain. There are several reasons why remote sensing is more reasonable than in situ observations, sampling and measurements, and land surveying. The costs are usually lower (namely in the case when reasonably large areas are monitored or the area is monitored periodically), measurement does not require a direct access to the monitored area (e.g. useful in the case of swamplands), accuracy and spatial resolution is adequate for monitoring, and data measured in various parts of the electromagnetic spectrum are available (in the case of proper sensors). Multispectral and hyperspectral imagery is important for land cover monitoring because of possibility of calculation 
of various spectral indices, which are suitable for land cover identification. Satellite or aerial imagery is suitable for monitoring larger areas. UAVs are increasingly used to monitor smaller areas, e.g. small water bodies (ponds), mainly because of faster data collection, data collection on demand, higher spatial resolution, and lower costs in comparison to aerial imagery collection (Iizuka et al., 2018; Pásler, Komárková and Sedlák, 2015; Salamí, Barrado and Pastor, 2014).

The aim of the paper is to propose a suitable way of monitoring small water bodies and land cover changes in the surroundings, which is based on data collected by a middle-class UAV and visible spectral indices (based on red, green, and blue bands). It extends the study of Cermakova, Komarkova and Sedlak (2019). At first, a suitable way of utilization of a UAV for data collection is described. Next, several visible sspectral indices (CIVE, ExG, ExR, ExG - ExR, GLI, and VARI) are calculated from the collected data. Evaluation of indices is the following part of the paper. Only a part of the selected pond and its surroundings are used to demonstrate the proposed procedure.

\section{STATE OF THE ART}

\section{Water Bodies and Land Cover Changes}

Identification of land use/land cover changes and their quality monitoring have been based on remotely sensed data since the 70s along with Landsat existence (Bukata, Harris and Bruton, 1974; Lin et al., 2014; Maleki et al., 2018; Pechanec et al., 2014; Saharan et al., 2018). Landsat data was successfully used for water bodies observation and identification of their shorelines many times, e.g. (Bhagat and Sonawane, 2011; Jiang et al., 2014; Jones et al., 2017; Nandi et al., 2016).

Many articles were particularly focused on various water bodies and their shorelines. In some cases, the observation takes many years, e.g. (Gallop et al., 2015). This study observed changes of shoreline in the period of 34 years in southwestern Australia. Aerial photographs were used as a data source. It was realized that over $96 \%$ of beaches straightened during the time period. In this case, there were large changes in shoreline position that did not correspond to the indices of annual wave conditions. In future, researches want to use fuzzy-based computer algorithms. (Nandi et al., 2016) used the Digital Shoreline Analysis System (DSAS) for the detection of changes of shoreline in a monitored area. DSAS is a special extension of United States Geological Survey, which can calculate the rate of shoreline change.

Small water inland bodies identification from remotely sensed data was emphasized as a specific issue by several authors, e.g. (Cermakova, Komarkova and Sedlak, 2019; Haas, Bartholomé and Combal, 2009; Jones et al., 2017; Li et al., 2015; Ogilvie et al., 2018; Pásler, Komárková and Sedlák, 2015). In the Czech Republic, e.g. water erosion of the river Trkmanka shoreline (a small stream in South Moravia) was studied in (Pechanec et al., 2015). They focused on erosion susceptibility and shoreline changes because of the destructive influences of water erosion on the soil surface. This method provides the maximum volume of soil erosion caused by water.

\section{Unmanned Aerial Vehicles for Monitoring}

UAVs can provide very low elevation and very high-resolution data on demand, of course with respect to limitations given by law regulations and weather conditions (Iizuka et al., 2018; Lejot et al., 2007; Pásler, Komárková and Sedlák, 2015).

UAVs are increasingly used for monitoring land cover/land use changes (Feng, Liu and Gong, 2015; Iizuka et al., 2018; Salamí, Barrado and Pastor, 2014) and natural disasters, e.g. floods or earthquakes (Abdelkader et al., 2013; Casado et al., 2018). It is a reasonably cheap and fast possibility of how to determine the situation in the observed area. It can be used as an early warning before e.g. landslide or pond failure, or to fast monitor impacts of a disaster because the changes of monitored area and situation are observable immediately. So, utilization of UAVs for prevention and monitoring actual situation can save money and peoples' lives. Using an UAV for floods warning is also possible according to (Srikudkao et al., 2015). The study is focused on creating a basis for floods warning systems and prevention systems. (Abdelkader et al., 2013) presented a novel flood sensing architecture to monitor large scale desert hydrological basins surrounding metropolitan areas, based on unmanned air vehicles. The reason for their proposal was that the satellite-based weather forecast was not enough reliable. On the opposite, a combination of UAV and mobile microsensors using many parameters provided more accurate results.

Spectral visible indices based on red $(R)$, green $(G)$, and blue $(B)$ bands are increasingly used to process data from low-cost and middle-class UAVs. Many indices have been proposed for an agriculture and phenological purposes - to observe vegetation, its growth, and its health status, e.g. CIVE - Colour Index of Vegetation Extraction (Kataoka et al., 2003), ExG - Excess Green (Woebbecke et al., 1995), ExR - Excess Red (Meyer, Hindman and Laksmi, 1999), ExG - ExR difference (Meyer et al., 2004), GLI - Green Leaf Index (Louhaichi, Borman and Johnson, 2001), NExG - Normalized Excess Green (Woebbecke et al., 1995), NGRDI - Normalized 
Table 1. Used spectral indices and their formulas

\begin{tabular}{lll}
\hline Index & Formula & \\
\hline CIVE & $0.441 * \mathrm{R}-0.81 * \mathrm{G}+0.385 * \mathrm{~B}+18.78745$ & (Kataoka et al., 2003) \\
& $\begin{array}{l}2 * \mathrm{~g}-\mathrm{r}-\mathrm{b} \\
\text { components are normalized: } \\
\mathrm{g}=\mathrm{G} /(\mathrm{R}+\mathrm{G}+\mathrm{B}) \\
\mathrm{r}=\mathrm{R} /(\mathrm{R}+\mathrm{G}+\mathrm{B}) \\
\mathrm{b}=\mathrm{B} /(\mathrm{R}+\mathrm{G}+\mathrm{B})\end{array}$ & (Woebbecke et al., 1995) \\
& $1.3 * \mathrm{R}-\mathrm{G}$ & \\
\hline ExR & ExG $-\mathrm{ExR}$ & (Meyer, Hindman and Laksmi, 1999) \\
\hline ExG - ExR $(\mathrm{ExGR})$ & (Meyer et al., 2004) \\
\hline GLI & $\left(2^{*} \mathrm{G}-\mathrm{R}-\mathrm{B}\right) /\left(2^{*} \mathrm{G}+\mathrm{R}+\mathrm{B}\right)$ & (Louhaichi, Borman and Johnson, 2001) \\
\hline VARI & $(\mathrm{G}-\mathrm{R}) /(\mathrm{G}+\mathrm{R}-\mathrm{B})$ & (Gitelson et al., 2002) \\
\hline
\end{tabular}

Red-Green Difference Index (Tucker, 1979), RGBVI - Red-Green-Blue Vegetation Index (Bendig et al., 2015), VARI - Visible Atmospherically Resistant Index (Gitelson et al., 2002), and many others.

Shorelines can be used to autonomously navigate UAVs as proposed by (Baker and Kamgar-Parsi, 2010). A near-infrared sensor allows the vision system to distinguish water from land. The vision system then issues commands to the autopilot to follow the coastline or the riverbank.

\section{CASE STUDY}

\section{Methods and Software}

The following visible spectral indices are calculated in the paper: CIVE, ExG, ExR, ExG - ExR, GLI, and VARI. All used indices, their formulas, and sources describes Table 1. GLI is focused on using reflectance of green vegetation cover to highlight it in the images (Louhaichi, Borman and Johnson, 2001). VARI is used to highlight vegetation in images as well (Gitelson et al., 2002). ExG uses the green part of the electromagnetic spectrum to highlight the green vegetation cover (Woebbecke et al., 1995).

DJI Ground Station on iOS was used for flights planning and DJI GO 4 for flights controlling. ENVI OneButton 5.0 was used for creating mosaics from particular images. QGIS Desktop (version 3.8.1) was used for calculation of vegetation indices. ArcGIS for Desktop (version 10.5.1) was used for next processing and cartographic visualisations.

\section{Area of Interest}

A western part of the pond Skrin, which is located close to city Lázně Bohdaneč city (the Pardubicky region, the Czech Republic), is used as an area of interest (see Figure 1). The total area of the pond is $0.27 \mathrm{~km}^{2}$ and the pond is used for fish farming (Czech Fishing Union, 2018). The area of interest is a flat area, which lies approx. 220 $\mathrm{m}$ a.s.l. It covers clear water surface, seasonally flooded greenery, various vegetation including tree crowns, dry reeds (including dry grass), and dry trees. 


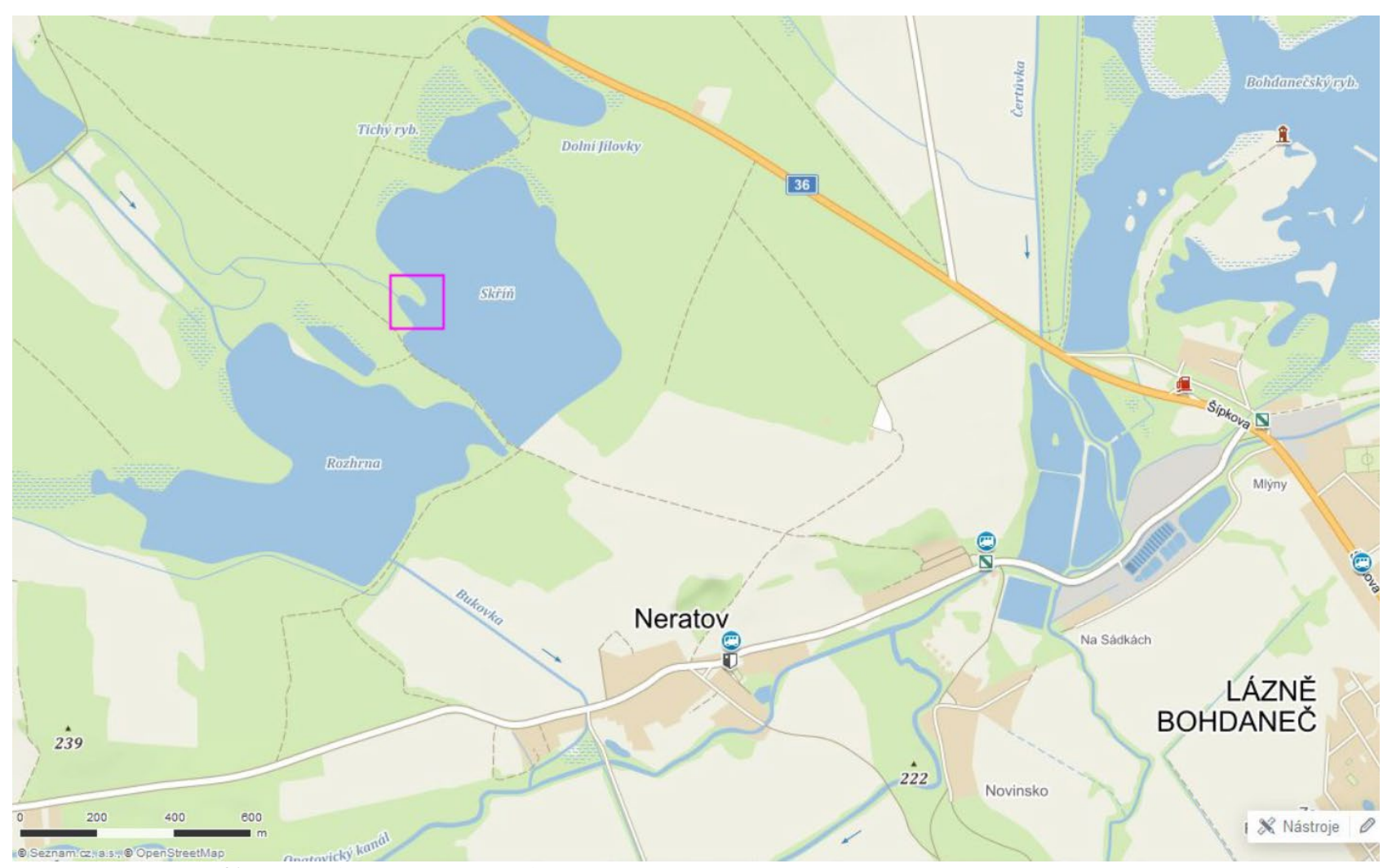

Figure 1. Area of interest (source: mapy.cz)

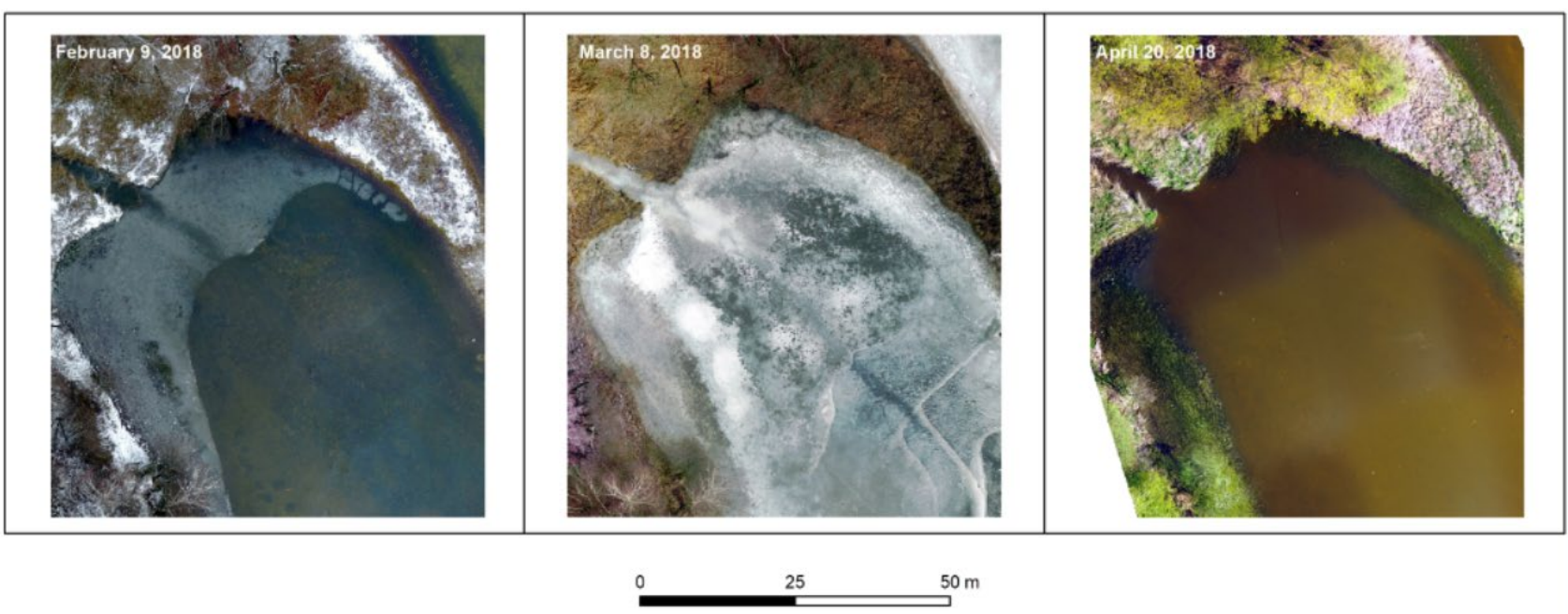

Figure 2. The appearance of the area of interest in the monitored period: February 9, 2018; March 8, 2018; April 5, 2018; and April 20, 2018

The appearance of the area during the monitored period was changing (see Figure 2). During the first flight (February 9, 2018), a part of the pond Skřrin was frozen. Simultaneously, some parts were covered by snow and there was no green vegetation. The whole area of the pond was frozen on March 8, 2018. Start of vegetation growth is visible in the last image - acquired on April 20, 2018.

\section{Data Collection and Pre-Processing}

Phantom 3 Professional with built-in 2,7K Ultra HD DJI camera was used for data collection. Camera has $1 / 2.3$ " CMOS sensor with $12.4 \mathrm{M}$ of effective pixels. Images from the DJI camera fixed on the Phantom 3 contain the visible bands (red, green, and blue) only. Phantom 3 has the following characteristics: weight $1216 \mathrm{~g}, 4$ motors, max. speed $16 \mathrm{~m} . \mathrm{s}^{-1}$, max. range $1000 \mathrm{~m}$, max. flight time 25 minutes. (DJI, 2018). The drone itself (including the DJI camera) costs approx. $700-800$ Eur (DJI, 2018).

Images were acquired once per a month. Particular dates were influenced by weather conditions and vegetation changes, which are fast in April. The Pond Skř́ń was observed in the following dates: February 9, 2018; March 8, 2018; and April 20, 2018. In all cases, images were acquired between $9-10 \mathrm{am}$. The route of the recording was 

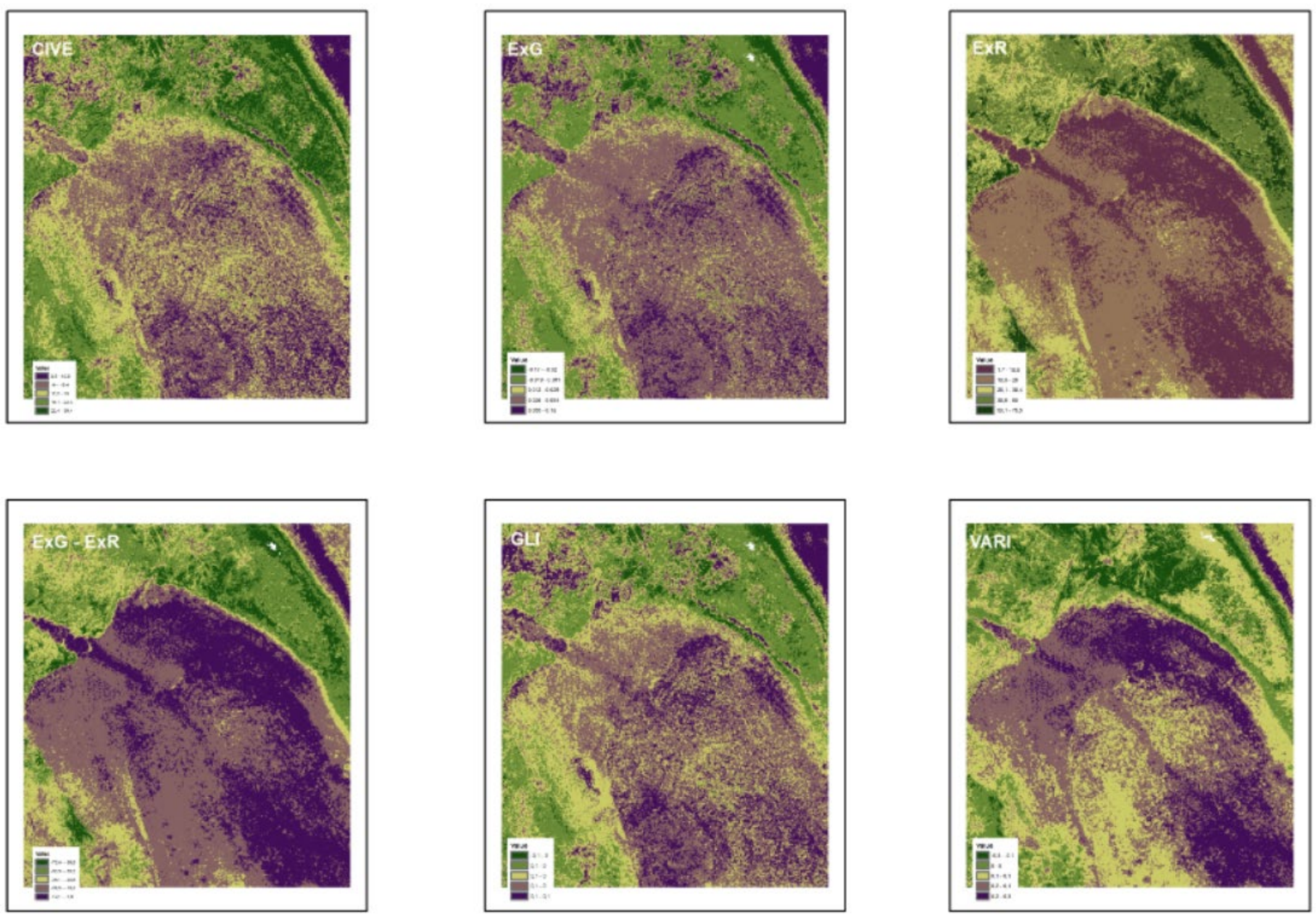

Figure 3. Spectral indices for the area on February 9, 2018, after low pass filtering

planned in advance in DJI Ground Station and it was the same in all cases. All images were acquired during one flight lasting approx. $15 \mathrm{~min}$. The total length of the flight was $1545 \mathrm{~m}$, size of the covered area was $0.0285 \mathrm{~m}^{2}$. The flight was planned in 7 lines with both front and side overlap $60 \%$ and at $39.6 \mathrm{~m}$ of altitude. In total, 64 images were acquired during each flight. Spatial resolution is $1.7 \mathrm{~cm}$ per pixel.

The atmospheric correction was not calculated because of the low altitude, a short time span, and good weather conditions. Information about coordinates is recorded during the flight by the software. Verification of the location was conducted by a comparison with aerial imagery provided by the State Administration of Land Surveying and Cadastre in a form of WMS at the first stage. ENVI OneButton is used as a tool to correct particular images and mosaic them to create an output orthorectified mosaic with WGS 84 - UTM zone 33 as the coordinate system.

\section{Data Analysis - Visible Spectral Indices}

The following indices were calculated: CIVE, ExG, ExR, ExG - ExR, GLI, and VARI for all three mosaics. Next, low-pass filtering on a $3 \times 3$ window (ArcGIS tool Filter) was used as a post-processing tool. Visualization of the results was the last step. Visualization in a form of classifies raster was chosen and 'Natural breaks - Jenks' was used as a classification method in ArcGIS. 'Pink to YellowGreen Diverging, Dark' scheme was used for visualization purposes. To simplify interpretation, we preferred to use pink/violet colour for all water forms and green for all vegetation forms.

Because of the different appearance of the landscape in the three involved months and limited possibilities of visible spectral indices, each index provides the most information value for another time period and land cover. Figures $3-5$ show results. 

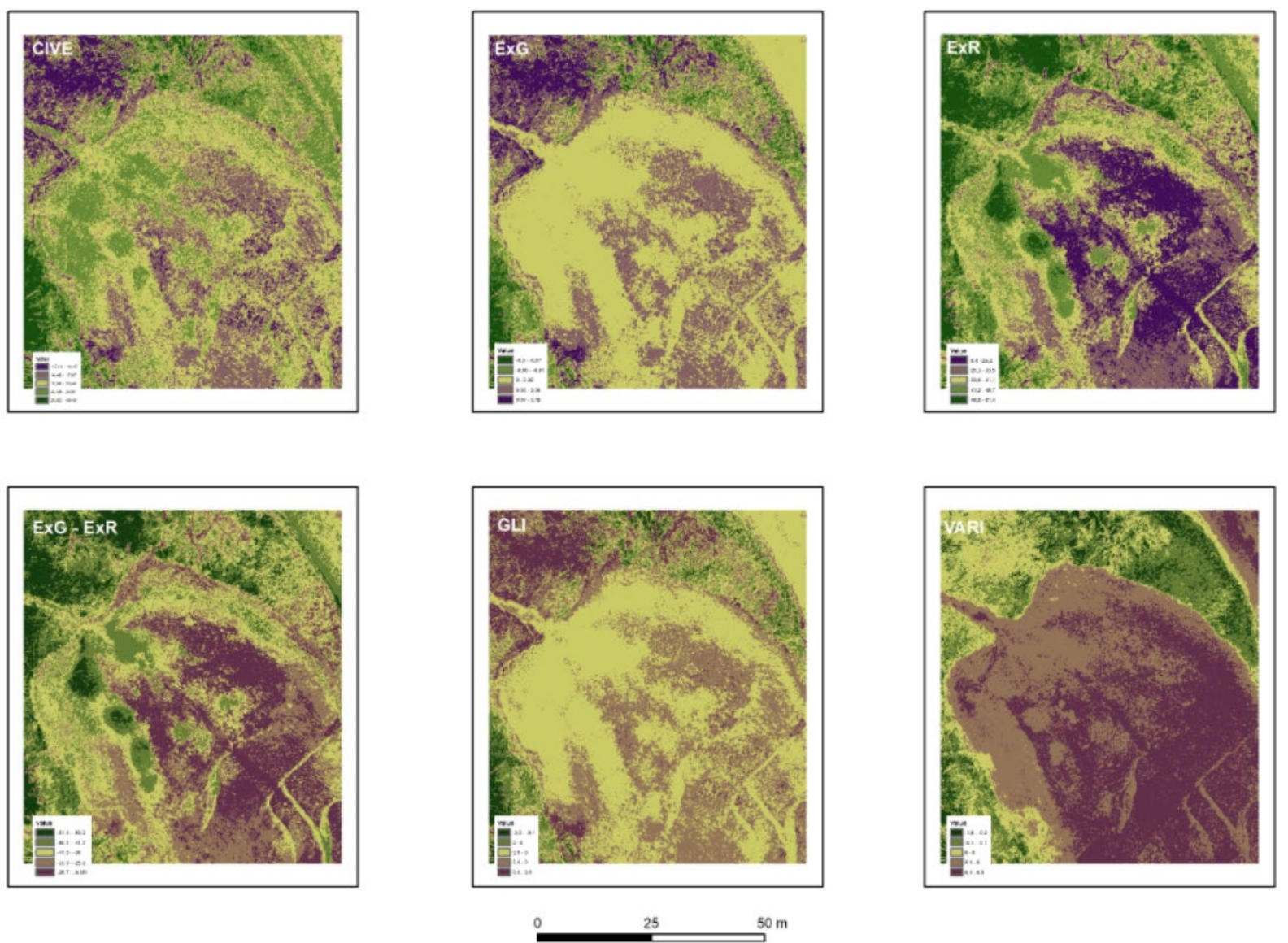

Figure 4. Spectral indices for the area on March 8, 2018, after low pass filtering
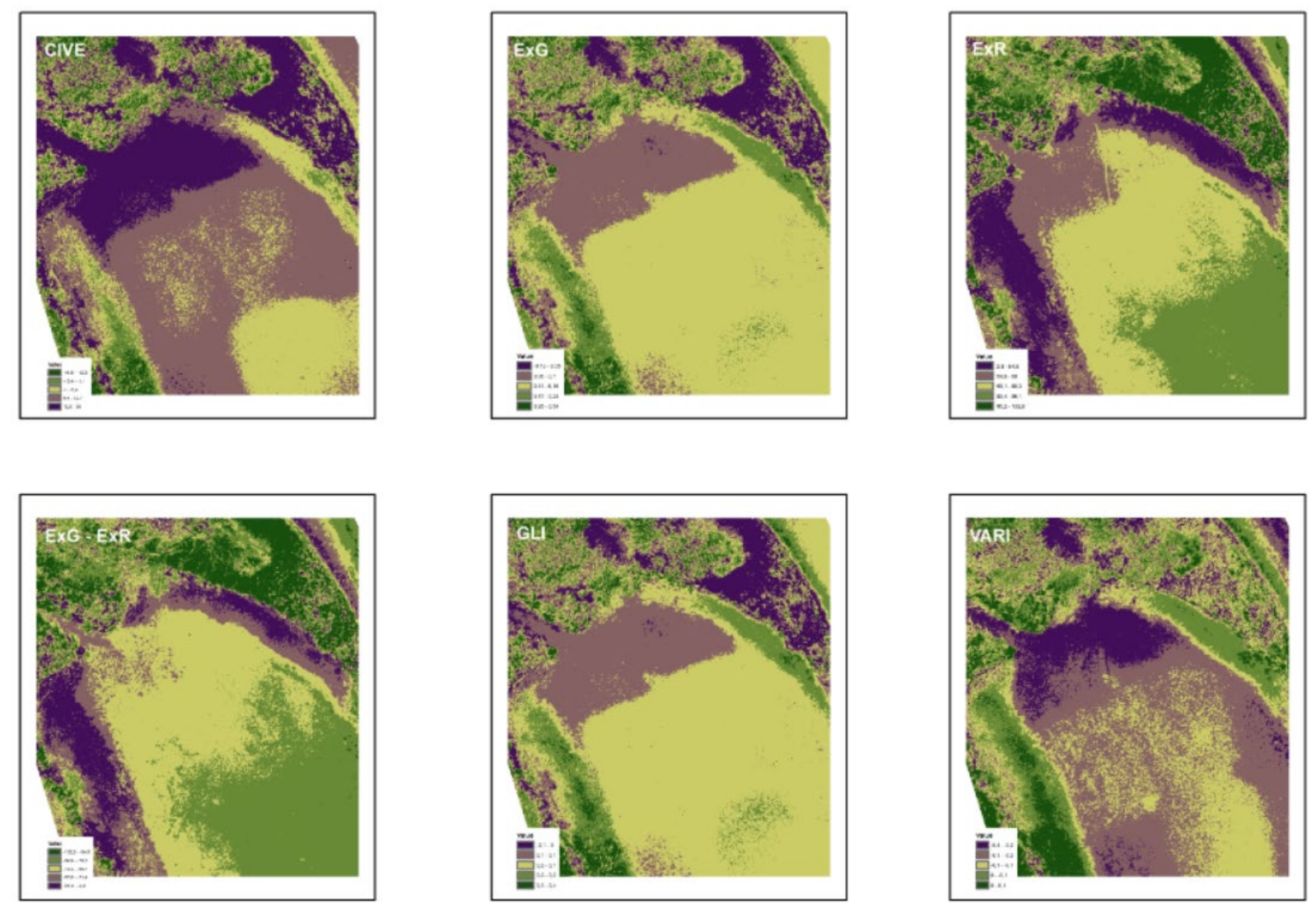

Figure 5. Spectral indices for the area on April 20, 2018, after low pass filtering 


\section{DISCUSSION}

Cermakova, Komarkova and Sedlak (2019) shows calculations of the land cover changes in the area of interest in the observed period. It is clear that the changes are significant. In this article we extend utilization of visible spectral indices by involving other indices, by low-pass filtering and by a fast but yet useful visualization.

Difference ExG - ExR together with VARI allows a highlighting of frozen water surface. Almost all indices support green vegetation identification as it can be seen in Figure 5. CIVE, ExG, and GLI well highlight a green vegetation. CIVE and VARI are able to highlight a clear water surface. All of the indices allow distinguishing a seasonally flooded vegetation from the surrounding land covers.

The results were compared with visual interpretation and field observation. A small size of the area of interest and a very-high spatial resolution of the images allows utilization of this method. After comparison of both methods, it is clear that land cover changes can be observed in the monitored time period.

The key question is if regional state administration bodies will be able to use UAVs as a tool to quickly and cheaply identify land cover changes, not only of the small water bodies. Or if the state administration bodies will still use traditional data sources, which provide lover spatial resolution, or which may be more expensive and less frequently available.

\section{CONCLUSIONS}

Land use and land cover changes monitoring is increasingly important with respect to a sustainable development. Climate changes and natural disasters, e.g. droughts in the last years, can be used as example of monitoring drivers. Water and water sources belong to the key contemporary sources and issues. Researches are still mainly focused on a world or national level of the water bodies monitoring, but the regional level of this issue is important as well, mainly for the citizens of the region.

This is one of the reasons why the article is focused on a small water body - a pond Skřrin and its surroundings, which is located close to Lázně Bohdaneč city in the Czech Republic. A middle-class UAV (Phantom 3 Pro) was used for the data acquisition because it represents a quick and cheap way how to collect the spatial data with a very-high spatial resolution. In this case, the images were acquired from the camera sensing in the visible bands only.

The monitoring of the part of the pond and its surrounding was conducted 3 times: February 9, 2018; March 8, 2018; and April 20, 2018. For the study of changes, visible spectral indices were used. The indices are based on different reflectivity of various land covers and mostly highlight the green vegetation. All of them require the availability of red, green, and blue bands only.

In the article, there are calculated various visible spectral indices, which use only visible bands. The calculated indices are the following ones: CIVE, ExG, ExR, ExG - ExR, GLI, and VARI.

Visual comparison was used in this case because of the small size of the area and high resolution of the images. It is clearly visible that the water area changed during the monitored time period.

The article shows that it is possible to identify land cover types and to monitor land cover changes on demand and using a low-cost middle-class UAV. UAV allows data acquisition on demand, of course with a respect to legal and weather limitations. Spatial resolution of acquired data is very high (centimetres level). Middle-class UAVs are usually equipped with a standard visible (RGB) camera. The article demonstrates the ease of utilization of this type of UAV for land cover identification and its changes monitoring.

\section{ACKNOWLEDGEMENT}

Authors thank the University of Pardubice, Students grant competition, SGS_2019_17 project for the support.

\section{REFERENCES}

Abdelkader, M., et al. (2013). A UAV based system for real time flash flood monitoring in desert environments using Lagrangian microsensors. In 2013 International Conference on Unmanned Aircraft Systems (ICUAS), pp. 25-34. https://doi.org/10.1109/ICUAS.2013.6564670

Baker, P. and Kamgar-Parsi, B. (2010). Using shorelines for autonomous air vehicle guidance. Computer Vision and Image Understanding. Information Technology Division, Naval Research Laboratory, Washington, DC 20375, United States, 114(6), 723-729. https://doi.org/10.1016/j.cviu.2010.01.009 
Bendig, J., et al. (2015). Combining UAV-based plant height from crop surface models, visible, and near infrared vegetation indices for biomass monitoring in barley. International Journal of Applied Earth Observation and Geoinformation. Institute of Geography, GIS and RS Group, University of Cologne, Albertus-Magnus-Platz, Cologne, 50923, Germany, 39, pp. 79-87. https://doi.org/10.1016/j.jag.2015.02.012

Bhagat, V. S. and Sonawane, K. R. (2011). Use of Landsat ETM+ data for delineation of water bodies in hilly zones. Journal of Hydroinformatics, 13(4), 661-671. https://doi.org/10.2166/hydro.2010.018

Bukata, R. P., Harris, G. P. and Bruton, J. E. (1974). The detection of suspended solids and chlorophyll-a utilizing digital multispectral ERTS-1 data. In Second Canadian Symposium on Remote Sensing, pp. 551-564.

Casado, M. R., et al. (2018). The use of unmanned aerial vehicles to estimate direct tangible losses to residential properties from flood events: A case study of Cockermouth Following the Desmond Storm. Remote Sensing. School ofWater, Energy and Environment, Cranfield University, College Road, Cranfield, MK430AL, United Kingdom, 10(10). https://doi.org/10.3390/rs10101548

Cermakova, I., Komarkova, J. and Sedlak, P. (2019). Calculation of Visible Spectral Indices from UAV-Based Data: Small Water Bodies Monitoring. In 2019 14th Iberian Conference on Information Systems and Technologies (CISTI), pp. 1-5. https://doi.org/10.23919/CISTI.2019.8760609

Czech Fishing Union (2018). Available at: www.rybsvaz.cz (Accessed: 28 August 2018).

DJI (2018). Available at: https:/ /www.dji.com (Accessed: 28 August 2018).

Feng, Q., Liu, J. and Gong, J. (2015). UAV Remote sensing for urban vegetation mapping using random forest and texture analysis. Remote Sensing. State Key Laboratory of Remote Sensing Science, Institute of Remote Sensing and Digital Earth Chinese Academy of Sciences, No.20, Datun Road, Chaoyang District, Beijing, 100101, China, 7(1), 1074-1094. https://doi.org/10.3390/rs70101074

Gallop, S. L., et al. (2015). The impact of temperate reefs on 34 years of shoreline and vegetation line stability at Yanchep, southwestern Australia and implications for coastal setback. Marine Geology, 369, 224-232. https:// doi.org/10.1016/j.margeo.2015.09.001

Gitelson, A. A., et al. (2002). Novel algorithms for remote estimation of vegetation fraction. Remote Sensing of Environment, 80(1), 76-87. https://doi.org/10.1016/S0034-4257(01)00289-9

Haas, E. M., Bartholomé, E. and Combal, B. (2009). Time series analysis of optical remote sensing data for the mapping of temporary surface water bodies in sub-Saharan western Africa. Journal of Hydrology, 370(1-4), 5263. https:// doi.org/10.1016/j.jhydrol.2009.02.052

Iizuka, K., et al. (2018). Advantages of unmanned aerial vehicle (UAV) photogrammetry for landscape analysis compared with satellite data: A case study of postmining sites in Indonesia. Cogent Geoscience, 4(1). https://doi.org/10.1080/23312041.2018.1498180

Jiang, H., et al. (2014). An automated method for extracting rivers and lakes from Landsat imagery. Remote Sensing, 6(6), 5067-5089. https://doi.org/10.3390/rs6065067

Jones, S. K., et al. (2017). Big data and multiple methods for mapping small reservoirs: Comparing accuracies for applications in agricultural landscapes. Remote Sensing, 9(12). https:// doi.org/10.3390/rs9121307

Kataoka, T., et al. (2003). Crop growth estimation system using machine vision. In Proceedings 2003 IEEE/ ASME International Conference on Advanced Intelligent Mechatronics (AIM 2003), Japan, pp. 1079-1083. https://doi.org/10.1109/AIM.2003.1225492

Lejot, J., et al. (2007). Very high spatial resolution imagery for channel bathymetry and topography from an unmanned mapping controlled platform. Earth Surface Processes and Landforms, 32(11), 1705-1725. https://doi.org/10.1002/esp.1595

Li, H., et al. (2015). Flood monitoring in Hainan Island based on HJ-CCD data. Nongye Gongcheng Xuebao/Transactions of the Chinese Society of Agricultural Engineering, 31(17), 191-198. https://doi.org/10.11975/j.issn.1002-6819.2015.17.025

Lin, Y., et al. (2014). Correlating analysis on spatio-temporal variation of LUCC and water resources based on remote sensing data. In Proceedings of SPIE - The International Society for Optical Engineering, China. https:// doi.org/10.1117/12.2063843

Louhaichi, M., Borman, M. M. and Johnson, D. E. (2001). Spatially located platform and aerial photography for documentation of grazing impacts on wheat. Geocarto International, 16(1), 65-70. https:// doi.org/10.1080/10106040108542184

Maleki, S., et al. (2018). Application of Remote Sensing in Monitoring Unsustainable Wetlands: Case Study Hamun Wetland. Journal of the Indian Society of Remote Sensing, 46(11), 1871-1879. https://doi.org/10.1007/s12524-0180842-7

Meyer, G. E., et al. (2004). Intensified fuzzy clusters for classifying plant, soil, and residue regions of interest from color images. Computers and Electronics in Agriculture, 42(3), 161-180. https://doi.org/10.1016/j.compag.2003.08.002 
Meyer, G. E., Hindman, T. and Laksmi, K. (1999). Machine vision detection parameters for plant species identification. Proceedings of SPIE - The International Society for Optical Engineering, United States, 3543, pp. $327-335$. Available at: https://www.scopus.com/inward/record.uri?eid=2-s2.0-0032636094\&partnerID=40\&md5= 34630f1675107f6dc64809d2e2e26d08

Nandi, S., et al. (2016). Shoreline shifting and its prediction using remote sensing and GIS techniques: a case study of Sagar Island, West Bengal (India). Journal of Coastal Conservation, 20(1), 61-80. https:/ / doi.org/10.1007/s11852-015-0418-4

Ogilvie, A., et al. (2018). Combining Landsat observations with hydrological modelling for improved surface water monitoring of small lakes. Journal of Hydrology, 566, 109-121. https:/ / doi.org/10.1016/j.jhydrol.2018.08.076

Pásler, M., Komárková, J. and Sedlák, P. (2015). Comparison of possibilities of UAV and Landsat in observation of small inland water bodies. In International Conference on Information Society, i-Society 2015, Czech Republic, pp. 45-49. https://doi.org/10.1109/i-Society.2015.7366855

Pechanec, V., et al. (2014). Analyses of moisture parameters and biomass of vegetation cover in southeast Moravia. International Journal of Remote Sensing, 35(3), 967-987. https:/ / doi.org/10.1080/01431161.2013.875236

Pechanec, V., et al. (2015). Decision support tool for the evaluation of landscapes. Ecological Informatics, 30, 305308. https://doi.org/10.1016/j.ecoinf.2015.06.006

Saharan, M. A., et al. (2018). Classification and assessment of the land use - Land cover changes in Jodhpur city using remote sensing technologies. In International Archives of the Photogrammetry, Remote Sensing and Spatial Information Sciences - ISPRS Archives, India, pp. 767-771. Available at: https://www.scopus.com/inward/record. uri?eid=2-s2.0-85057629755\&partnerID =40\&md5=df8448a4596bd5fc26c45a796c605382

Salamí, E., Barrado, C. and Pastor, E. (2014). UAV flight experiments applied to the remote sensing of vegetated areas. Remote Sensing, 6(11), 11051-11081. https://doi.org/10.3390/rs61111051

Srikudkao, B., et al. (2015). Flood warning and management schemes with drone emulator using ultrasonic and image processing. Advances in Intelligent Systems and Computing, 107-116. https://doi.org/10.1007/978-3-31919024-2_11

Tucker, C. J. (1979). Red and photographic infrared linear combinations for monitoring vegetation. Remote Sensing of Environment, 8(2), 127-150. https:/ / doi.org/10.1016/0034-4257(79)90013-0

Woebbecke, D. M., et al. (1995). Color indices for weed identification under various soil, residue, and lighting conditions. Transactions of the American Society of Agricultural Engineers, 38(1), $259-269$. https://doi.org/10.13031/2013.27838 